\title{
Infantile T-cell Acute Lymphoblastic Leukaemia: A Case Report
}

\author{
Natasha Baig1, Sadia Muhammad', Sumaira Shaikh² \\ 'Department of Paediatric Oncology, The Indus Hospital and Health Network, Karachi, Pakistan, \\ ${ }^{2}$ Department of Pathology, The Indus Hospital and Health Network, Karachi, Pakistan
}

Received: 12 December 2021/Accepted: 22 December 2021

\section{Open acCess Correspondence: \\ Natasha Baig, Plot C-76, Sector 31/5, Opposite Darussalam Society, Korangi Crossing, Karachi - 751 90, Pakistan. E-mail: natasha.humayun@tih. org.pk}

Citation: Baig N, Muhammad S, Shaikh S. Infantile T-cell Acute Lymphoblastic Leukaemia: A Case Report. J Cancer Allied Spec [Internet]. 2021 Dec 20;8(1):1-6.XXX https://doi.org/10.37029/jcas. v8i1.459

Copyright: (c) 2022 Baig, et al. This is an open access article distributed under the terms of the Creative Commons Attribution License, which permits unrestricted use, distribution, and reproduction in any medium, provided the original author and source are credited.

Funding: This research received no specific grant from any funding agency in the public, commercial or not-for-profit sectors.

Competing interest: Nil.

\section{Introduction}

Acute lymphoblastic leukaemia (ALL) is the most commonly presenting paediatric malignancy. Despite improvement in treatment strategies and cure rates in recent years, it remains a pertinent cause of morbidity and mortality. ${ }^{[1]} \mathrm{ALL}$ is more commonly diagnosed as B-cell lineage ALL (B-ALL) in infants. However, T-cell lineage ALL (T-ALL) is an exceedingly rare presentation under 1 year of

\begin{abstract}
Introduction: Acute lymphoblastic leukaemia (ALL) is the most common malignancy in children, with a male predominance. Paediatric ALL is usually of B-cell lineage; T-cell leukaemia is uncommon and extremely rare under 1 year of age. Mixed-lineage leukaemia gene rearrangement is the best-known hallmark of infantile leukaemia and is a poor prognostic indicator. While multiagent high-dose chemotherapy remains the first line of treatment for paediatric T-cell lineage ALL (T-ALL), there are numerous side effects of these regimens, and most patients undergo relapse. Due to the rarity of the disease, treatment protocols for infantile T-ALL have not been established to date. Clinical Description: We present a case of a 7-month-old Pakistani male that presented with fever and cough and was subsequently diagnosed with T-cell ALL. T-ALL was diagnosed on flow cytometry. Due to poor prognosis, the patient was assigned palliative care. Practical Implications: Management of infantile leukaemia has yet to be studied in-depth. With a lack of clear treatment guidelines, the approach toward these patients remains challenging. Further research and clinical trials in this area of study are paramount to improving clinical outcomes for these young patients.
\end{abstract}

Key words: Acute lymphoblastic leukaemia, leukaemia, neoplasms, paediatric oncology, T-cell leukaemia, T-cell lineage acute lymphoblastic leukaemia age. Childhood and infantile T-ALL are distinctly different on a genetic and molecular level.[1] Multiagent high-dose chemotherapy is the first line of treatment for paediatric T-ALL, and children respond reasonably well, but not without longterm side effects. ${ }^{[2]}$ However, due to the paucity of literature on infantile T-ALL, targeted therapies and treatment protocols have not yet been developed for this tumour entity. 
Here, we present a case of a male infant with T-ALL and discuss the challenges in diagnosis and lack of clear treatment options. Written informed consent was obtained from the patient's father to publish this case report and all accompanying images.

\section{Case Presentation}

A 7-month-old Pakistani male presented to the paediatric emergency of a welfare hospital with fever and cough. The patient was lethargic, irritable and unwell for over 3 weeks. The patient had no significant birth history, previous hospitalisations or past illnesses. Family history reported by the parents was not positive for any malignancies or known genetic conditions. On examination, bilateral crepitations were noted in the chest. Regional lymph nodes were not palpable, the abdominal examination was unremarkable and no ecchymosis or petechiae were observed.

\section{Diagnosis and management}

The patient was admitted for investigations and symptomatic management. Complete blood count showed mild anaemia and leucocytosis with a white blood cell (WBC) count of $183.7 \times 10^{9} /$. Atypical lymphoid cells with coarse nuclear chromatin were observed on a peripheral smear [Figures 1 and 2]. Derangements were noted in certain baseline investigations (C-reactive protein $21.60 \mathrm{mg} / \mathrm{L}$, gamma-glutamyltransferase $712 \mathrm{U} / \mathrm{L}$ and alkaline phosphatase $840 \mathrm{U} / \mathrm{L}$ ), with most other parameters falling within normal ranges. Chest X-ray showed bilateral parahilar vascular haze, raising suspicion of a pulmonary source of infection. A mediastinal mass was not seen. The patient was started on antibiotics and supportive management with close monitoring for clinical improvement. With suspicion of leukaemia, flow cytometry [Figure 3] was performed, which confirmed the diagnosis of T-ALL.

On day 5, after the initial presentation, the patient was started on prednisone with regular checks on blood investigation. The WBC count showed a decreasing trend at $21.6 \times 10^{9} / 1$ with $68 \%$



Figure 1: Atypical lymphoid cells with coarse nuclear chromatin on peripheral smear

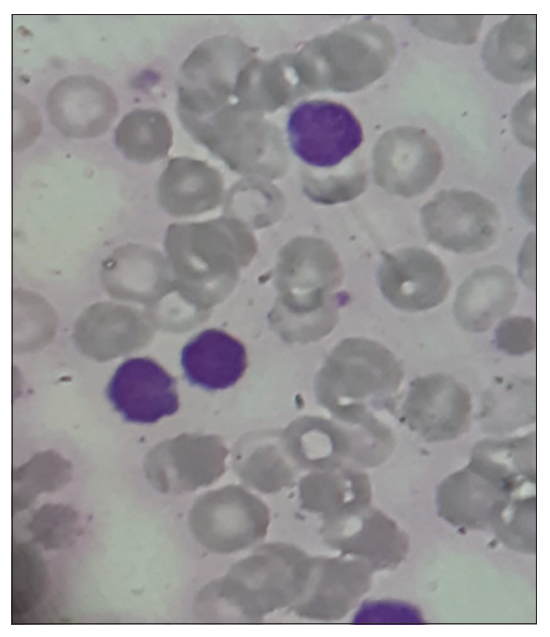

Figure 2: Atypical lymphoid cells with coarse nuclear chromatin were observed on peripheral smear

lymphocytes. Fluorescence in situ hybridisation was also conducted, which exhibited that mixedlineage leukaemia (MLL) gene was not rearranged. Therefore, the disease was classified as the central nervous system 1 and prophase 7.

A multidisciplinary team meeting concluded that the intensive chemotherapy regimen required for the treatment of this infant would not be favourable considering the poor prognosis of the disease. The patient's family was counselled, and with their consent, the patient was shifted to palliative care. Five weeks after the initial presentation, the 


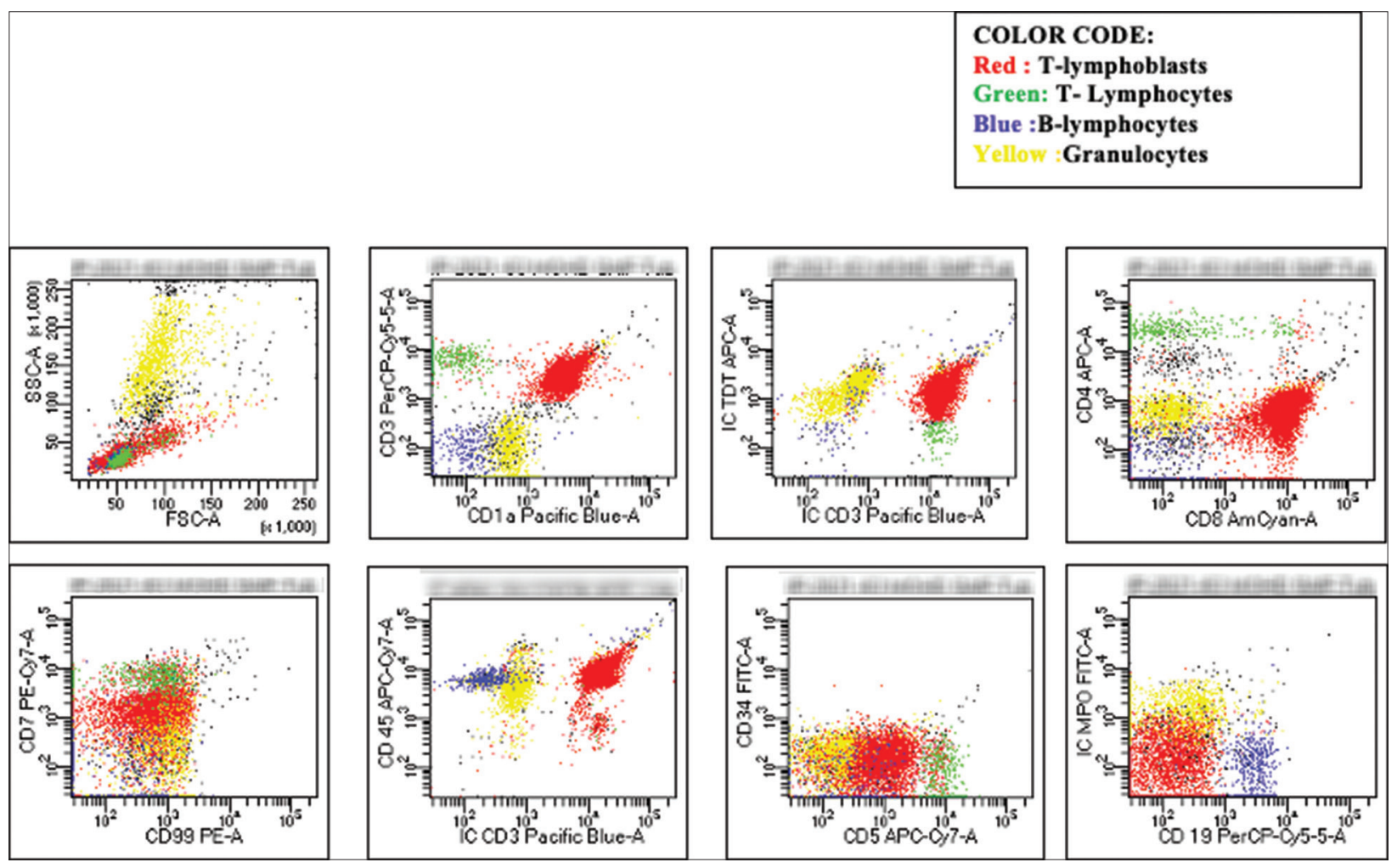

Figures 3: Flow cytometry showing $74.7 \%$ small- to medium-sized lymphoblasts (forward light scatter properties) exhibiting following phenotype; TdT (-), CD34(-), CD99(-), CD117(-), CD45(+), CD3 (+), surface CD3(+), CD4(-), $\mathrm{CD} 8(+), \mathrm{CD} 5(\mathrm{Dim}+), \mathrm{CD} 1 \mathrm{a}(+), \mathrm{CD} 7(+)$, intracytoplasmic myeloperoxidase (-), CD13 (-), CD34 (-), CD45 (+), CD19 (-), CD20 (-) and CD10 (-)

patient presented with fever and a generalised rash diagnosed as measles, making a complete recovery after treatment. The most recent investigations showed the patient's WBC count at $14.2 \times 10^{9} / \mathrm{I}$ with regular monitoring in the palliation clinic every 2 weeks.

\section{Discussion}

T-ALL accounts for approximately $15 \%$ of childhood ALL cases. ${ }^{[2]}$ Even with multiagent chemotherapy treatment, $15 \%$ of paediatric T-ALL cases undergo relapse and present an overall dismal prognosis. ${ }^{[2]}$ Adverse prognostic factors for ALL in children include age $<1$ year or $\geq 10$ years, male gender, WBC count $\geq 50,000 / \mathrm{mm}^{3}$ and African, Hispanic and native American ethnicities. ${ }^{[3]}$ A higher expression of the USP7 allele in Africans has been identified as a novel risk locus. ${ }^{[4]}$ Similarly, myeloid leukaemia factor 1 (MLF1) gene deletion has been identified as a plausible marker for infantile TLL, ${ }^{[5]}$ whereas deletion of the SCL/TAL1 interrupting locus (STIL)-T-cell acute leukaemia (TAL1) (STILTAL1) fusion gene has been seen in paediatric T-ALL. ${ }^{[6]}$ The presence of a phosphatase and tensin homolog (PTEN) gene deletion has previously been discovered at birth in an infant with T-ALL, suggesting an in utero origination of this disease..$^{[5]}$

However, rearrangements involving the MLL gene (also known as KMT2A) at chromosome band $11 \mathrm{q} 23$ are the best-known hallmark of infantile leukaemia. ${ }^{7]}$ Infants with wild-type MLL genes such as our patient have been observed to present after the age of 6 months with more favourable WBC counts and more mature immunophenotypes, as well as a good response to 7-day prednisone monotherapy. ${ }^{[8]}$ Among 
infants with wild-type MLL ALL, low levels of MEIS1 expression have been proven to have a superior clinical outcome with a 5-year disease-free survival (DFS) of 87.5 compared to a high MEIS1 expression DFS of 50.0 and 5-year overall survival (OS) of 100.0 and 71.4 for low and high MEIS1 expression, respectively. ${ }^{[8]}$ Thus, the significant influence of MEIS1 expression on survival rates highlights that this category of infant ALL is highly aggressive leukaemia. ${ }^{[8]}$

For unclear reasons, increasing age within infants with ALL is associated with a better clinical outcome. ${ }^{[8]}$ However, infantile ALL has an overall lower survival rate than ALL in older children and adolescents. ${ }^{[9]}$ The Interfant-06 treatment protocol study established a correlation between younger age at diagnosis and an inferior outcome, with a 6-year event-free survival (EFS) of $25.1 \%$ for patients aged 0-3 years. ${ }^{[10]}$ Furthermore, T-ALL is known to have a skewed gender distribution with 3 times greater prevalence in males than females, most likely due to ubiquitously transcribed tetratricopeptide repeat, $X$ chromosome (UTX) being an X-linked tumour suppressor gene. ${ }^{[11]}$

The main prognostic measure in $T-A L L$ is a minimal residual disease (MRD), and treatment is usually directed by end-of-consolidation MRD response. ${ }^{[12]}$ Glucocorticoids are the cornerstone for T-ALL treatment but are known to paradoxically induce steroid resistance by upregulation of the expression of IL-7 receptors. ${ }^{[13]}$ Decreased expression of the wild-type MLL gene has also been proven to contribute to glucocorticoid resistance in ALL. ${ }^{[14]}$

The Interfant protocols are the most widely studied treatment regimens for infantile ALL. After treatment with the Interfant protocols, the 4-year EFS for infantile T-ALL was 45.7\%, and the 6-year OS of infant ALL with germline KMT2A was 87\%. ${ }^{[10]}$ However, these are intensive regimens comprising multiple phases of treatment and are associated with complications including infections, mucositis and liver and neurotoxicity. ${ }^{[15]}$ Compared to Berlin-Frankfurt-Münster (BFM)-based childhood ALL protocols, the Interfant protocols have shown comparable treatment-related mortality with no improvement in survival and a high rate of deaths in complete remission. ${ }^{[16]}$ Hence, there is a dire need for improved therapeutic strategies targeting treatment-related toxicity to improve mortality and reduce relapse rates. ${ }^{[16]}$

Two methotrexate (MTX) intensification regimens: High-dose MTX (HDMTX) with leucovorin rescue and Capizzi-style escalating intravenous MTX without leucovorin rescue, plus pegaspargase Capizzi-style, and intravenous MTX (C-MTX) were studied in the Children's Oncology Group (COG) AALL0434 trial.. ${ }^{[17]}$ More recently, a 4-drug induction regimen with dexamethasone and an anthracycline, plus augmented BFM-like consolidation containing cyclophosphamide, has been recommended for children with T-cell ALL. ${ }^{[18]}$ Nelarabine and vincristine are the first-line treatment options for relapsed $T-A L^{[19]}$ but are associated with significant, fatal toxicities. ${ }^{[20,21]}$

The treatment outcomes for paediatric ALL in Pakistan are subpar because developing countries face a unique set of challenges such as limited access to specialised oncology care units, unavailability of supportive care, nutritional deficiencies, financial constraints and lack of parental education. ${ }^{[22,23]}$ Consequently, patients are more likely to present late with more severe disease or abandon treatment and are more susceptible to infectious complications. ${ }^{[23]}$ Oneweek prednisolone prophase in a cohort of Pakistani children with ALL was useful in stabilising and reducing disease burden. ${ }^{[24]}$ Compared to $14 \%$ of induction deaths when direct multiagent chemotherapy was administered, prednisolone prophase was associated with a decreased death rate of $9 \% .{ }^{[24]}$ Therefore, considering the poor prognosis of infantile T-ALL and considering the factors above, a palliative treatment strategy is usually adopted in Pakistan. Despite being a rare presentation, further research and clinical trials must be done to treat and manage infantile T-ALL to 
establish a clearer clinical approach toward these young patients and improve clinical outcomes.

\section{References}

1. Doerrenberg $M$, Kloetgen $A$, Hezaveh K, Wössmann W, Bleckmann K, Stanulla M, et al. T-cell acute lymphoblastic leukemia in infants has distinct genetic and epigenetic features compared to childhood cases. Genes Chromosomes Cancer 2017;56:159-67.

2. Durinck K, Goossens S, Peirs S, Wallaert A, van Loocke W, Matthijssens F, et al. Novel biological insights in T-cell acute lymphoblastic leukemia. Exp Hematol 2015;43:625-39.

3. Hunger SP, Mullighan CG. Acute lymphoblastic leukemia in children. N Engl J Med 2015;373:1541-52.

4. Qian M, Zhao X, Devidas M, Yang W, GochoY, Smith C, et al. Genome-wide association study of susceptibility loci for T-cell acute lymphoblastic leukemia in children. J Natl Cancer Inst 2019;111:1350-7.

5. Mansur MB, van Delft FW, Colman SM, Furness CL, Gibson J, Emerenciano M, et al. Distinctive genotypes in infants with T-cell acute lymphoblastic leukaemia. Br J Haematol 2015;171:574-84.

6. Gustafsson BM, Mattsson K, Bogdanovic G, Leijonhufvud G, Honkaniemi E, Ramme K, et al. Origins ofSTIL-TAL1 fusion genes in children who later developed paediatric T-cell acute lymphoblastic leukaemia: An investigation of neonatal blood spots. Pediatr Blood Cancer 2018;65:e27310.

7. Jung R, Jacobs U, Krumbholz M, Langer T, Keller T, de Lorenzo $\mathrm{P}$, et al. Bimodal distribution of genomic MLL breakpoints in infant acute lymphoblastic leukemia treatment. Leukemia 2010;24:903-7.

8. van der Linden $\mathrm{MH}$, Boer JM, Schneider $\mathrm{P}$, Willekes $\mathrm{M}$, Seslija L, de Lorenzo P, et al. Clinical and molecular genetic characterization of wild-type MLL infant acute lymphoblastic leukemia identifies few recurrent abnormalities. Haematologica 2016;101:e95-8.

9. Dores GM, Devesa SS, Curtis RE, Linet MS, Morton LM. Acute leukemia incidence and patient survival among children and adults in the United States, 2001-2007. Blood 2012;119:34-43.

10. Pieters R, De Lorenzo P, Ancliffe P, Aversa LA, Brethon B, Biondi $A$, et al. Outcome of infants younger than 1 year with acute lymphoblastic leukemia treated with the interfant-06 protocol: Results from an international phase III randomized study. J Clin Oncol 2019;37:2246-56.

11. van der Meulen J, Sanghvi V, Mavrakis K, Durinck K, Fang F, Matthijssens F, et al. The H3K27me3 demethylase UTX is a gender-specific tumor suppressor in T-cell acute lymphoblastic leukemia. Blood 2015;125:13-21.
12. Raetz EA, Teachey DT. T-cell acute lymphoblastic leukemia. Hematology Am Soc Hematol Educ Program 2016;2016:580-8.

13. Meyer LK, Huang BJ, Delgado-Martin C, Roy RP, Hechmer A, Wandler AM, et al. Glucocorticoids paradoxically facilitate steroid resistance in $\mathrm{T}$ cell acute lymphoblastic leukemias and thymocytes. J Clin Invest 2020;130:863-76.

14. Beesley $A H$, Rampellini JL, Palmer ML, Heng JY, Samuels AL, Firth MJ, et al. Influence of wild-type MLL on glucocorticoid sensitivity and response to DNAdamage in pediatric acute lymphoblastic leukemia. Mol Cancer 2010;9:284.

15. Pieters R, Schrappe M, de Lorenzo P, Hann I, de Rossi G, Felice $M$, et al. A treatment protocol for infants younger than 1 year with acute lymphoblastic leukaemia (Interfant-99): An observational study and a multicentre randomised trial. Lancet 2007;370:240-50.

16. Pennella CL, Deu MA, Rossi JG, Baialardo EM, Alonso CN, Rubio $P$, et al. No benefit of Interfant protocols compared to BFM-based protocols for infants with acute lymphoblastic leukemia. Results from an institution in Argentina. Pediatr Blood Cancer 2020;67:e28624.

17. Winter SS, Dunsmore KP, Devidas M, Wood BL, Esiashvili N, Chen $Z$, et al. Improved survival for children and young adults with T-lineage acute lymphoblastic leukemia: Results from the children's oncology group AALL0434 methotrexate randomization. J Clin Oncol 2018;36:2926-34.

18. Teachey DT, O'Connor D. How I treat newly diagnosed T-cell acute lymphoblastic leukemia and T-cell lymphoblastic lymphoma in children. Blood 2020;135:159-66.

19. McMahon CM, Luger SM. Relapsed T cell ALL: Current approaches and new directions. Curr Hematol Malig Rep 2019;14:83-93.

20. Kuhlen M, Bleckmann K, Möricke A, Schrappe M, Vieth S, Escherich G, et al. Neurotoxic side effects in children with refractory or relapsed $\mathrm{T}$-cell malignancies treated with nelarabine based therapy. Br J Haematol 2017;179:272-83.

21. Hartz B, Löbel U, Hagel C, Escherich G. Fatal neurological side-effects with necrosis of spinal cord following nelarabine treatment in a child with relapsed T-cell acute lymphoblastic leukemia. Am J Hematol 2013;88:1096-7.

22. Jabeen K, Ashraf MS, Iftikhar S, Belgaumi AF. The impact of socioeconomic factors on the outcome of childhood acute lymphoblastic leukemia (ALL) treatment in a low/middle income country (LMIC). J Pediatr Hematol Oncol 2016;38:587-96.

23. Khokhar MA, Ali MM, Liaqat S, Moin A, Sarwar HA, Sarwar MZ. A review of access to cancer facilities in Punjab, Pakistan. Cancer Rep 2020;3:e1245. 
24. Jabbar N, Mansoor N, Nadeem K, Maqsood S, ButtZ, Ashraf S. Prednisolone prophase for a week versus upfront multiagent chemotherapy in childhood acute lymphoblastic leukemia: An analysis with reference to induction mortality in a developing country. J Pediatr Hematol Oncol 2020;42:181-4.

\section{Authors' Contributions}

Conceived and designed the analysis: NB. Collected the data: NB. Contributed data or analysis tools: SM, SS. Performed the analysis: Not applicable. Wrote the paper: NB, SM, SS. 